Alchemy", he sketches the development of nuclear physics, from the early discoveries of radioactivity to the latest available publications. In this chapter he, as it were, sets the scene for the final denouement and introduces us to the leading characters. The sketch is, of course, far from complete as a history of fifty years of scientific effort; but Prof. Gamow has a good eye for the main points, and it is surprising how much exact information he has succeeded in compressing into these fifty-two pages. In the second section, "How the Stars use Atomic Energy", Prof. Gamow discusses in considerable detail the cosmic aspects of atomic energy, and the processes by which the energy of the universe, assumed to have been originally all in nuclear form, is being steadily transformed into the radiant light and heat from which all our sources of terrestrial energy are ultimately derived. Much work has recently been done on this subject, and the main outlines and some of the details are now becoming sufficiently clear and certain ; and this summary of the present position is very welcome. Few writers on the cosmical aspects of physics can avoid speculations, such as those which we enjoyed so much in the works of Eddington and Jeans, about the birth, progress and possible end of the universe, and Prof. Gamow is certainly not of their number. One may say that his account of the matter seems quite as convincing, and just as fascinating, as those of his predecessors in the field.

In the final section, "How can Man use Atomic Energy ?", the author gives an account of the physical principles underlying the purposive release of atomic energy, whether for destructive or for constructive purposes. Prof. Gamow's mastery of the subject is evident in every page of the text, though in fact he reveals nothing which was not implicit in Dr. Smyth's official report. In these times, when a scientific author must write with one eye on his readers and the other on the police, more could not be expected. However, the official report was so informative on the purely scientific aspects of the problem that Prof. Gamow has quite enough material available for his particular purpose. If there is one portion of the book where we might have hoped for rather more guidance from the author it is in the very brief concluding paragraphs on the peaceful uses of atomic power, on which a considerable amount of information has recently been released in the United States. Possibly Prof. Gamow considers that these economic and technical matters are outside the scope of his present book.

Although the book is entertainingly written, and entirely non-mathematical in character, it is a very serious attempt to present as complete a picture as possible of the atomic energy problem in its scientific aspects, and demands and deserves the close attention of the reader. Prof. Gamow has not shirked the undoubted difficulties of the subject, though he has taken great pains to alleviate them by numerous analogies, illustrations and graphs. What that somewhat hypothetical individual-the general reader-can make of it all must be left for him to discover. He is not likely to find a pleasanter or more competent guide to the subject. Any student about to begin a course on nuclear physics should certainly read the book in order to learn what it is all about; while any student who has just completed such a course might equally profitably read it in order to discover what it has all been about. Many physicists and other scientifically minded people, who realize that during these last few strenuous years they have been unable to keep abreast of this latest efflorescence of science, will thank Prof. Gamow for providing them with this opportunity of bringing their knowledge up to date. The more widely a knowledge of the potentialities for good or evil of this latest addition to our power resources is disseminated the better.

J. A. CROWTHER

\section{DAY BY DAY ON SKOKHOLM ISLAND}

\section{Letters from Skokholm}

By R. M. Lockley. Pp. $x+244$. (London: J. M. Dent and Sons, Ltd., 1947.) 15s. net.

THE letter form of composition has many advan. tages, particularly in describing the day-by-day happenings of a rural, or in this case an island, life. Mr. Lockley has written before of islands, and in particular of his own island of Skokholm off the Pembrokeshire coast of Wales; but he has by no means exhausted the interest and fascination of the subject, and we are glad he has recast the letters originally addressed to his brother-in-law, John Buxton, when a prisoner-of-war, and made them into a book.

In the first letter the author discusses why he went to live on Skokholm and the joys of simple living. He continues with various subjects, such as the history of the island and its occupation by man, beasts and birds. It was early populated by rabbits. There are documents dating back to 1324 which show how numerous they must have been. In the winter of 1387-88, 3,120 carcases were brought from the islands of "Schalmey, Schokolm and Middle. holm".

Since those days rabbits have continued to flourish on the islands and all attempts to exterminate them have failed. In $1936 \mathrm{Mr}$. Lockley, having tried trapping, ferreting, snares and nets without any really marked effect, resorted to a virus disease which it was hoped would be 100 per cent effective, but it was not. It had little or no effect.

The best results were achieved with 'Cyano-gas' and the rabbits were really reduced, enabling the author's farming operations to be conducted with much more success.

One of the most interesting letters is that which tells of an old cow grey seal coming ashore on an early October day to give birth to her calf. For four days she "did not stir from beside her child, which she fed at least three times a day, probably oftener. To watch the calf suck the retractable breasts, and to see Clementina" - as the mother had been dubbed - "paw and fondle her lovingly, very humanly, was a happy sight."

Mr. Lockley says that he has found grey seal calves dropped here any time between late July and late December, whereas on the north-west of Scot. land calving seems to be confined to September, October and November.

The author's letters cover a wide field, including bird migration and trapping of the migrants for identification and ringing purposes; $a$ visit to Grassholm and its gannets; the Manx shearwaters that throng in such numbers to Skokholm; and many other things. A brief review can but hint at his topics, but reference must be made to the admir. able illustrations executed by Mr. Charles Tunnicliffe, which are illustrations in fact as well as in name.

F. PITT 